Reprod. Nutr. Dévelop., 1988, 28 (2 B), 335-347.

\title{
Mammalian reproductive strategies : genes, photoperiod and latitude
}

\author{
F. H. BRONSON
}

Institute of Reproductive Biology, Zoology Department, University of Texas, Austin, Texas 78712 USA.

Summary. This paper considers how and why natural selection might promote or block the photoperiodic regulation of a mammal's reproduction. The factors most important in making this decision would seem to be the following: life expectancy, length of the female's cycle, feeding strategy, the presence or absence of survival mechanisms like hibernation, and the nature of the seasonal challenges offered by the mammal's habitat. A speculative scheme is offered for the potential utility of this type of regulation dependent upon life expectancy and latitude of residence.

\section{Introduction.}

Mammals often show seasonal variation in their reproduction. Sometimes this variation is dramatic, with both sexes limiting their reproductive capabilities to a restricted part of the year. Sometimes this limitation is seen in females, but not in males. Sometimes seasonal variation amounts to only a tendency for females, or both sexes, to concentrate their reproductive activities during one part of the year. Sometimes neither sex exhibits any seasonal tendency ; both exhibit a yeararound breeding capability.

In an ultimate sense, most cases of seasonal breeding reflect variation in a complex of dietary and climatic factors : food, rainfall, and temperature. All physiological processes are limited by the amount of available food. Rainfall and temperature determine plant growth and hence the amount of food available for plant-eating animals, which in turn are eaten by insectivores and carnivores. Temperature can exert more direct effects on reproduction as well. As has been noted many times now, wherever climate and diet vary seasonally natural selection will tend to favor reproduction during whatever season maximizes the potential for success.

Seasonally-changing habitats are the rule on this planet. At the higher latitudes the annual variation in temperature can be extreme. In the tropics temperature varies little but rainfall patterns can be strongly seasonal (Walter, 1971). Thus the expectation is that most mammals will show at least some seasonal tendency in their reproduction. Three factors intrinsic to the mammal 
itself can either ameliorate or potentiate this expectation. The first of these is life expectancy. Short-lived mammals must always gamble to some degree with their reproduction, whenever and wherever possible, in order to balance their high rate of mortality. Long-lived mammals can afford to be more selective. Thus all other factors being equal, short-lived mammals tend to be much less seasonal in their reproduction than long-lived mammals.

The second factor that modifies an expectation of reproductive seasonality relates to the mammal's feeding strategy. Mammals that feed only upon highly specific foods tend to be more strongly seasonal in their reproduction than mammals that have evolved a generalist feeding strategy. The latter can shift easily from one food source to another, thereby buffering seasonal change in the availability of specific foods. The third factor of importance here is the presence or absence of certain survival mechanisms that exaggerate the need for seasonal breeding. These include such phenomena as migration and hibernation.

When these intrinsic factors interact with the characteristics of the mammal's habitat to dictate seasonal breeding, this need may or may not be enforced directly by climatic and dietary variation. Sometimes climatic and dietary factors act both ultimately and proximately to promote seasonal breeding. In other cases natural selection opts to rely upon a proximal predictive cue such as photoperiod. Photoperiodic prediction allows metabolic preparation in advance of the most propitious season for reproduction. This may or may not be an advantage, depending upon the mammal of concern and the characteristics of its habitat.

The objective of this paper is to consider how and why natural selection might promote or block the use of photoperiodic cueing in relation to latitude in mammals. Latitude is the major determinant of annual variation in daylength, and it is a crude correlate of the potential for annual variation in temperature. It does not correlate well with rainfall patterns, however. Within the framework of these characteristics, then, the specific objective here is to explore the relationship between latitude and photoperiodic cueing to determine what is known about this relationship, what can be surmised, and what has yet to be learned.

\section{Selection for or against reproductive photoresponsiveness, in theory.}

The action of natural selection on a population's gene pool to either block or promote photoperiodic cueing is visualized schematically in Figure 1. The intrinsic and extrinsic factors that ultimately dictate the need for seasonal breeding are shown at the bottom of this figure. It is important to emphasize that these factors interact with each other. For example, the predictability of the annual changes in climate and diet experienced by a habitat is in part a function of the life span of the individual perceiving these changes. The simple fact that good and bad seasons alternate with each other on an annual basis is an adequate level of predictability for long-lived mammals, but not for most of our small mammals whose life expectancies in the wild are measured in weeks or a few months at best. 


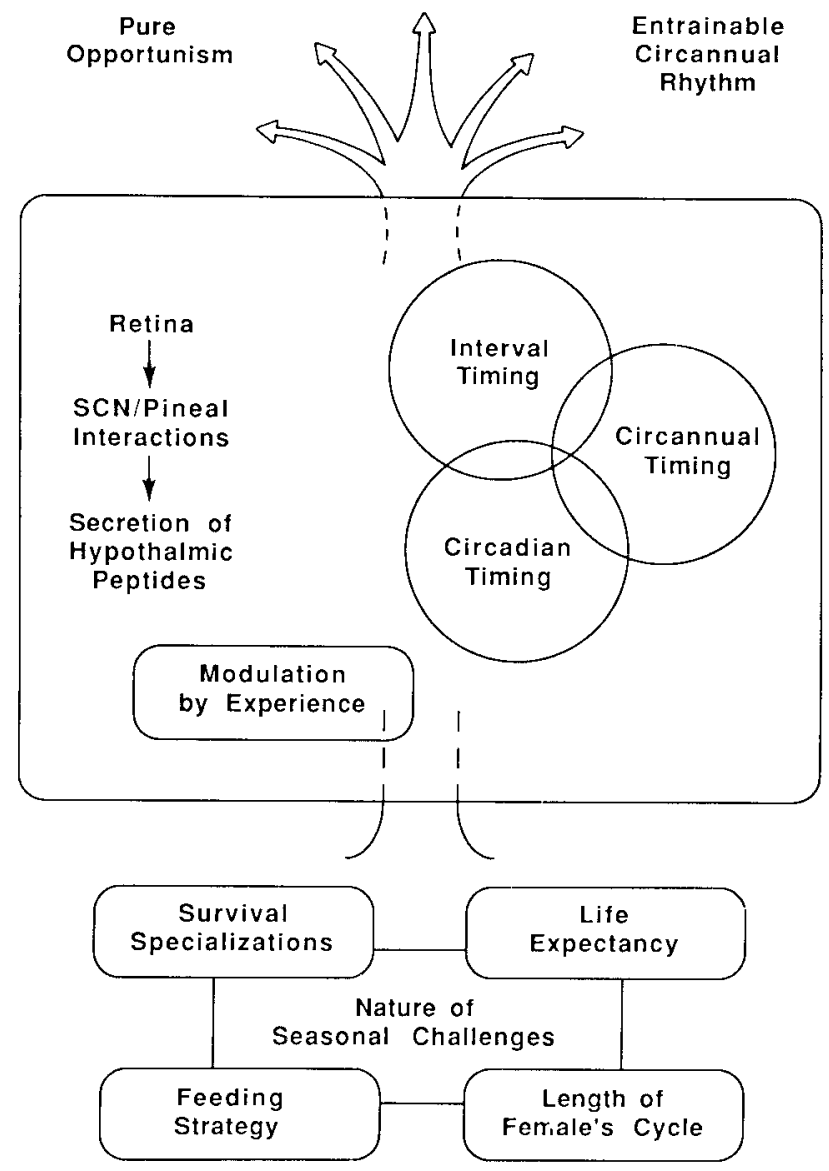

FIG. 1. - Schematic view of the way natural selection relies upon photoperiodic information to regulate reproduction in mammals.

A fourth intrinsic factor is shown as an interacting influence at the bottom of Figure 1 . This is the length of the female's reproductive cycle. More specifically it is the length of time from the onset of oogenesis to the most environmentallysensitive phase of the female's cycle. Usually this is late lactation when the female's energetic demands on her environment are greatest. The need for advance cueing increases as the length of time required for the female to produce her offspring increases.

The neural and neuroendocrine substrate for photoperiodic cueing is shown in the center of Figure 1. This is a greatly oversimplified version of physiological reality (c.f., Follett and Follett, 1981), but our concern here is not with the precise details of this substrate. Our concern is with how natural selection can manipulate it. In that vein then, Figure 1 assumes that mammals measure time relative to the phenomenon of seasonal breeding by using at least three general kinds of timing 
mechanisms : an entrainable circadian clock, an entrainable circannual clock and an interval timer whose characteristics vary qualitatively as well as quantitatively from the other two timing mechanisms. The latter concept was employed by Silver and Bittman (1984) to account for functions of less than 24 hours that are potentially rhythmic but which do not necessarily osciliate or reset. This concept is borrowed and altered here simply to acknowledge the mammal's ability to vary its sensitivity to photoperiod over periods of weeks or months, as has been demonstrated repeatedly now in the Syrian hamster (Elliott and Goldman, 1981).

The mammal's measurement of time is coupled to gonadotropin secretion by way of the now well known pathway involving the suprachiasmatic nucleus and the pineal. This pathway is the major concern of many of the papers presented at this symposium. Figure 1 assumes that all mammals possess at least some elements of this basic retina/SCN/pineal/hypothalamic peptide pathway. Also noted in Figure 1 is the fact that a mammal's experience can alter the critical photoperiod to which it reacts reproductively (e.g., Horton, 1984).

The presumption here is that the development and the functional integrity of the neural and neuroendocrine complexity shown at the core of Figure 1 reflects the actions of many genes. Depending upon the characteristics of a mammal's need to breed seasonally then, natural selection could act on many facets of this substrate to yield a large array of strategies related to the use of photoperiodic information. Natural selection could block or unblock reproductive responsiveness to photoperiod simply by manipulating any one of the many facets of the neuroendocrine pathway linking the mammal's measurement of time to gonadotropin secretion. Alternatively it could accomplish the same result by manipulating the linkage itself. The way photoperiodic information is used to enforce seasonal breeding probably is shaped by manipulating the timing mechanisms themselves.

The array of strategies resulting from such manipulations could range from pure opportunism, such as that shown by the non-photoperiodic house mouse and Norway rat (Davis, 1953 ; Bronson, 1979) to the rigid use of a circannual timing mechanism (see paper by Karsch in this volume). It is important to remember here that there are innumerable populations of mammals on this planet grouped by taxonomists into over 4.000 species. These species occupy over 50 distinctly different ecological niches (Eisenberg, 1981) in a wide variety of habitats all over the globe. Thus the diversity of strategies for using photoperiodic information in mammals as a whole must be impressive indeed.

\section{Latitude, annual breeding patterns and the use of photoperiod.}

The rapidity with which natural selection can alter a population's use of photoperiodic cueing, at least in short-lived animals, has been revealed now in a series of studies with mice of the genus Peromyscus. The many populations of the many species of this genus of rodent exist in all kinds of habitats from coast to coast and from the higher latitudes of the tropics almost to the arctic circle in North America (i.e., from about $15^{\circ}$ to over $60^{\circ}$ of latitude). 
There is immense variation in the annual patterns of reproduction in Peromyscus (Bronson, 1985). Around $60^{\circ}$ of latitude these animals exhibit a short two or three month breeding season during which they produce only a single litter. At $45^{\circ}$ of latitude they tend to show five to seven month breeding seasons, often with spring and or fall peaks, during which several litters are produced. Winter breeding is sometimes observed in some habitats at these latitudes. From $30^{\circ}$ to $45^{\circ}$ of latitude Peromyscus show a mixture of seasonal and non-seasonal patterns, with great year to year variation within a population. Below $30^{\circ}$ they mostly tend to breod year-around, although this tendency may not be realized in habitats with strongly seasonal rainfall patterns.

As demonstrated by Desjardins and Lopez (1980), Zucker et al. (1980), and Lynch et al. (1981), the use of photoperiodic prediction varies greatly between and even within populations of Peromyscus. Desjardins and Lopez (op. cit.), for example, found most (but not all) individuals to be reproductively photoresponsive in a population of deermice ( $P$. maniculatus) sampled in Alberta at $56^{\circ} \mathrm{N}$. About half of the individuals in a population of the same species in South Dakota $\left(44^{\circ} \mathrm{N}\right)$ were responsive, while none in a population from Texas $\left(30^{\circ} \mathrm{N}\right)$ were responsive.

The genetic basis for this variation has been established in the laboratory using selection techniques. This was done with the South Dakota population in which about half of the individuals were reproductively photoresponsive. Desjardins et al. (1986) reduced this proportion to less than one quarter in just two generations of selection against this trait. Selecting for photoresponsiveness rather than against it, another population was produced in which three quarters of the individuals were reproductively photoresponsive, also in just two generations.

Except in the northern part of its range, Peromyscus routinely produce two or more litters each year. Thus the proportion of deermice that are reproductively photoresponsive must be a highly labile statistic in the wild, shifting easily from year to year in the same population, and just as easily from one locale to another, all dependent upon momentary climatic and dietary considerations. Some individuals in some populations are able to find microclimates that permit reproduction during the winter. Those individuals that are non-photoperiodic will reproduce in these habitats, adding their genes to the gene pool when population density is lowest. Thus such heterogeneity is maintained, one trait or the other being emphasized at one time or another, or in one place or another.

How selection actually operates to mask and unmask this trait in Peromyscus is unknown. If the rat is any indication, it does so just by altering somehow the sensitivity of hypothalamic peptide secretion to melatonin (Wallen and Turek, 1981). On the other hand, the synthesis of melatonin itself has been blocked in one stock of laboratory mouse, apparently because of an inadvertent action of selection during domestication (Menaker, 1985). In all probability natural selection has found many ways to mask and unmask reproductive photoresponsiveness.

Deer of the genus Odocoileus provide a good contrast to Peromyscus. These are relatively long-lived animals that range from $50^{\circ}$ of latitude in southern Canada to the equator in South America. Outside of the tropics these animals breed only once a year. In sharp contrast to Peromyscus all temperate zone 
populations of Odocoileus show single, sharp, well-defined breeding seasons in the fall and early winter (Bronson, 1985) with little population to population variability. Non-seasonality begins to show up at about $25^{\circ}$ of latitude. Below $10^{\circ}$ these deer have evolved a post-partum estrus, thereby becoming continuous breeders. Every month finds females in some stage of reproduction, but there is little synchrony within a population. Interestingly, the males in some of these tropical populations of deer often exhibit what appears to be asynchronous freerunning annual cycles of androgen-dependent antler growth and shedding (Goss, 1983).

Populations of Odocoileus probably are uniformly reproductively photoresponsive from about $30^{\circ}$ to the northern edge of their range (Budde, 1983). As will be argued shortly, in all probability the tropical populations of this genus retain this trait in a selectively neutral state. At any rate, while not yet completely documented, the deer of this genus probably provide a good example of how long life expectancy promotes the routine use of photoperiodic prediction over a large range of latitudes, relative to the great within- and between-population variability seen in Peromyscus.

How generalizable are the latitudinal patterns seen in Peromyscus and Odocoileus? The immense variation seen in Peromyscus probably is quite generalizable to other short-lived rodents. The ubiquitous microtine rodents that are found throughout the world in the northern temperate and subpolar regions provide a case in point. Some populations of some species of microtines seem to be uniformly photoperiodic (e.g., the field vole, M. agrestis; Baker and Ranson, 1932). Some microtines are decidedly not photoperiodic despite living in the far north (e.g., the collared lemmings, Dicrostonyx groenlandicus, collected at $58^{\circ} \mathrm{N}$ by Hasler et al., 1976, and the Orkney vole $M$. orchadensii from $59^{\circ} \mathrm{N}$, collected by Marshall and Wilkinson, 1957). Two species of microtines seem best described as « marginally photoperiodic »: the population of montane voles, $M$. montanus, studied by Pinter and Negus (1965) and the population of meadow voles, M. pennsy/vanicus, examined by Dark et al. (1983).

One species of microtine, the field vole (Microtus arvalis), is known to be highly variable with regard to photoperiodism from population to population in Europe (c.f. Dobrowolska and Gromadzka-Ostrowska, 1983 ; Rychnovsky, 1985). Though not proven, this probably is true for many of the microtines noted above also. Importantly, winter breeding by some individuals in some microtine populations occurs sporadically even above the arctic circle in Finland (Kaikusalo and Tast, 1984). It occurs more commonly in Sweden and Britain (e.g., Hansson, 1984 and Smyth, 1966, respectively). Unfortunately none of these populations have been tested in the laboratory for genetic heterogeneity, therefore this remains only a presumption, albeit a reasonable one.

The latitudinal pattern seen in deer probably is also representative of large numbers of long-lived species living in the temperature zone. Many temperate zone lagomorphs, carnivores, ungulates and marsupials have been studied in the field, and many have been tested for reproductive photoresponsiveness in the laboratory. Most show strongly seasonal patterns of reproduction in the wild and 
most are reproductively photoresponsive in the laboratory (see Nelson, 1984). There are many interesting exceptions here, however (Bronson, 1988).

What about the tropics? Four out of every five species of mammals dwell in the tropics. Unfortunately, most physiologists and ecologists interested in reproduction live and work in the temperate zone. The result is a mismatch of endeavor and need. In general, one finds both seasonal and continuous breeding in the tropics with insufficient information available now to determine which of these patterns is most typical (Sadleir, 1969 ; Bronson, 1988).

Figure 2 shows what probably is a typical set of breeding patterns seen in a reasonably typical tropical environment. The llanos of Venezuela is a harshly seasonal grassland located somewhat above and below $8^{\circ}$ of latitude. There is only about one hour of variation in daylength at this latitude and little meaningful variation in temperature. Rainfall and hence plant growth is dramatically seaso'al, however, and one result is a strongly seasonal pattern of breeding in the marsupial mouse (Marmosa robinsoni). This small marsupial exhibits a highly specialized feeding strategy. Furthermore, it is relatively long-lived for its size. In contrast, the short-lived, generalist-feeding, cane mouse (Zygodontomys brevicauda) breeds continuously, as do most other short-lived rodents on the llanos (O'Connell, 1981).

Two-thirds of all mammalian species are rodents or bats. The latter are particularly interesting in the present context because they have radiated broadly in the tropics. As reviewed by Racey (1982), almost every conceivable annual pattern of reproduction can be seen in tropical bats. Some breed only once a year with good population synchrony. Often this is correlated with rainfall patterns and sometimes with the production of particular fruits. Other bats show bimodal patterns of reproduction each year, again in relation to rainfall. Many bats in the tropics breed continuously with little population synchrony.

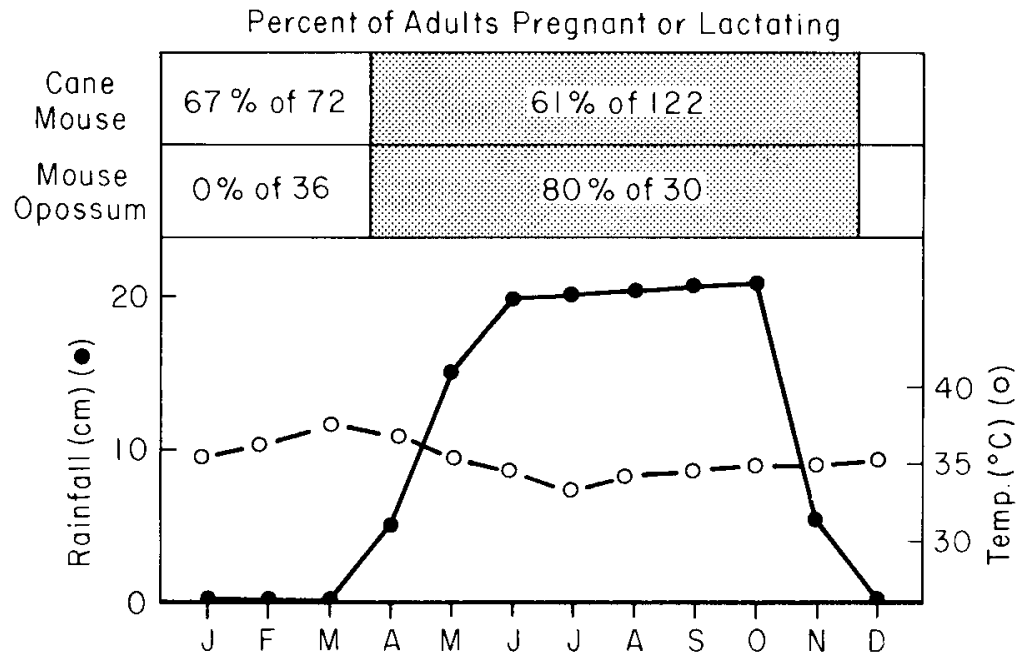

FIG. 2. - The annual pattern of reproduction in two mammals in relation to environmental conditions on the llanos region in Venezuela (redrawn from O'Connell, 1981). 
To my knowledge only three tropical mammals have been tested in the laboratory for reproductive photoresponsiveness : two lemurs from Madagascar (Petter-Rousseaux, 1970 ; van Horn and Resko, 1977), and the musk shrew (Suncus murinus) from Guam at $14^{\circ} \mathrm{N}$ latitude. The latter is a particularly interesting case since it acts like an ecological opportunist, sometimes living commensally with man and sometimes not, but always breeding continuously, year-around, wherever it has been studied, including temperate Japan. Nevertheless, gonadal steroidogenesis (but not gametogenesis) is decidedly photoresponsive in both sexes of the musk shrew from Guam in the laboratory (Rissman et al., 1987). The best explanation for this phenomenon is simply that reproductive photoresponsiveness in the Guam population is a relic from another time and another place. Obviously the capacity to respond reproductively to photoperiod can be carried in a gene pool as a selectively neutral trait in the tropics, even if not used.

\section{A speculative model for the relationship between latitude and photoperiodic cueing.}

In the absence of information from the lower latitudes where most mammals live, one can only speculate about latitude and photoperiodic cueing. A speculation based upon variation in life expectancy is offered in Figure 3. Only the northern half of the western hemisphere is shown here, but the presumption is that this scheme, if true, would apply to the rest of the world as well. In any case, this scheme is not meant to be an end in itself. It is only a challenge to other researchers to collect the kinds of information that would either verify or disprove it.

An assumption inherent in Figure 3 is that mammals cannot use less than one or two hours of annual variation in daylength to modulate their reproduction in the wild. The domesticated and inbred Syrian hamster can do much better than this in the controlled confines of the laboratory, of course (Elliott, 1976). The problem facing a wild population is different, however. How could a population of genetically diverse individuals, each influenced by a somewhat different set of environmental variables, achieve a reasonable degree of sexual synchrony when daylength is changing only a few seconds a day? The answer of course is that they could not, unless they utilized supplementary pheromonal mechanisms to enhance synchrony.

This is an interesting possibility that deserves exploration. Some individuals in the middle latitudes of the tropics could respond to their own genetically-fixed critical daylength, thereby stimulating other individuals pheromonally who, in turn, would stimulate still more individuals, and so forth, in a cascading effect. This could produce population-wide synchrony. It has been argued that this is what accounts for seasonality in many tropical primates (see Herndon, 1983). In the absence of more information on this possibility, however, Figure 3 assumes a minimum variation of one to two hours in daylength. 


\section{Life Expectancy}

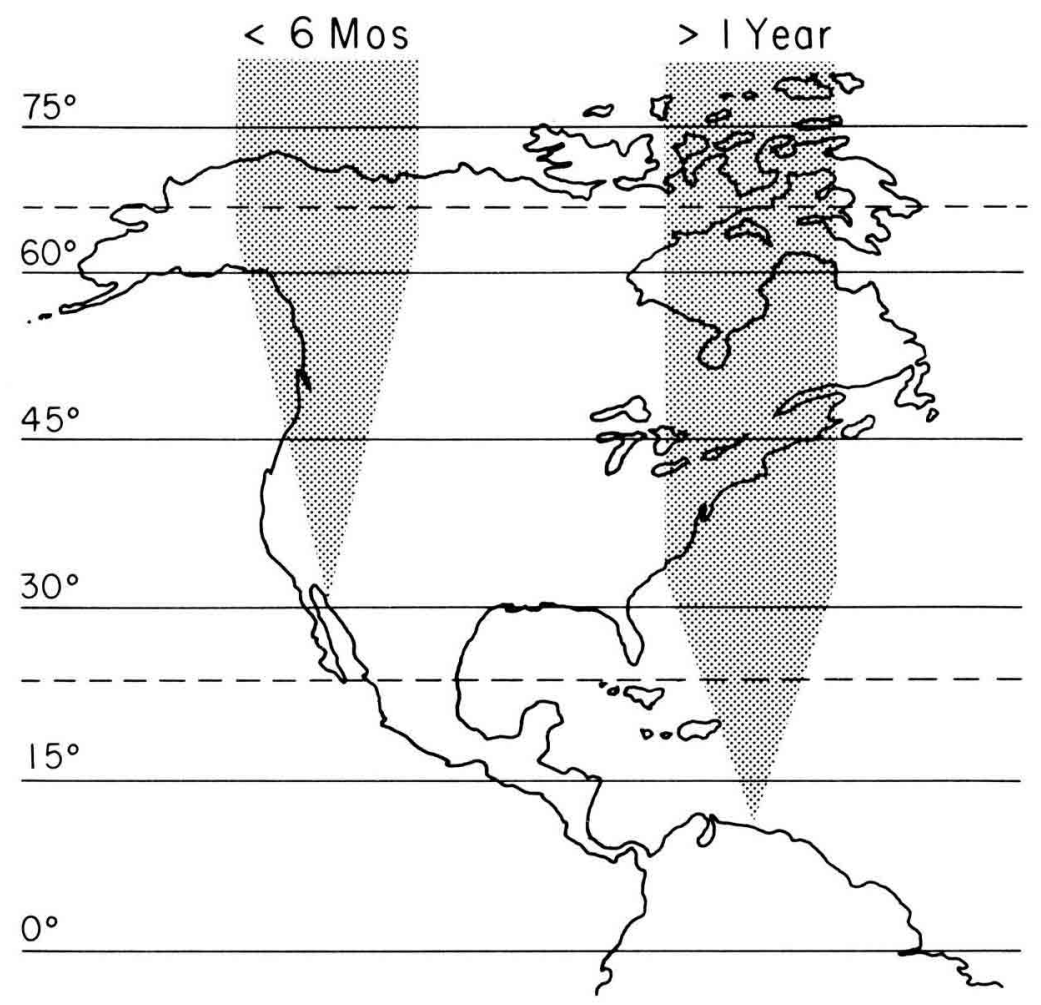

FIG. 3. - Speculative relationship between reproductive photoresponsiveness and latitude in short- and long-lived mammals.

As noted earlier, short-lived mammals must always be somewhat opportunistic in their reproductive strategies. A rigid use of photoperiodic cueing, uninfluenced by other factors, does not allow such flexibility. Thus Figure 3 suggests that photoperiodic cueing is probably of universal importance to shortlived mammals only at the very highest latitudes, and possibly not even there. The reports of occasional winter breeding in microtines at the arctic circle are illuminating indeed, particularly since few short-lived mammals live at or above this latitude.

There probably is a broad range between $30^{\circ}$ to $60^{\circ}$ of latitude in which some populations of short-lived animals routinely fix photoperiodic cueing, some routinely block it, and many are heterogeneous for it, all depending upon the precise set of environmental challenges facing each population. Indeed, genetic heterogeneity of this trait within a population is probably a routine consequence of natural selection operating in short-lived animals at these latitudes, simply because all habitats are somewhat unpredictable for mammals having life expectancies measured in weeks or a few months. 
Short-lived mammals living in the $30^{\circ}$ to $60^{\circ}$ range of latitudes probably also routinely use multiple cueing to supplement photoperiodic regulation, when present, thereby allowing still more flexibility (Bronson and Perrigo, 1987). They probably also routinely modify their critical daylength by experience, again promoting flexibility. Below $30^{\circ}$ of latitude most of these animals probably breed purely opportunistically in relation to rainfall (e.g., Dieterlen, 1985 ; Delany and Neal, 1969 ; Lam, 1983). The capacity to respond reproductively to short daylength probably is carried along as a selectively neutral trait in many of these animals, however, depending upon their evolutionary history.

As far as longer-lived mammals are concerned, certainly pure opportunism can be seen occasionally in the temperate zone. Two examples are the spotted hyena (Crocuta crocuta) in southern Africa (Lindeque and Skinner, 1982) and the red kangaroo (Macropus rufus) in arid Australia (Newsome, 1965). On the other hand, like deer, most long-lived mammals routinely breed seasonally at these latitudes, and they probably routinely do so in response to variation in daylength. Long-lived females tend to have long reproductive cycles and this accentuates the need for advance cueing. For the same reason one would not expect to often find population heterogeneity in these animals at these latitudes, nor would one expect to see much modulation of critical daylength by experience. Thus, Figure 3 suggests that photoperiodic cueing is more or less a constant in long-lived mammals that live above $30^{\circ}$ of latitude.

Below $30^{\circ}$ one probably finds a relatively narrow band of latitudes where photoperiodic cueing is selected for or against depending upon local conditions. Below this band one probably finds this trait carried in a selectively neutral state in some populations (or in some individuals) and not in others. Again, unknown here is the potential importance of pheromonal cueing as a supplement to allow photoperiodic cueing to penetrate deeper into the tropics, and the possibility that plant predictors could be used in the same way (e.g., Whitten, 1983).

\section{Conclusions.}

Photoperiodic enforcement of reproduction is an ancient phenomenon in both plants and animals. This trait probably has been selected for, masked, unmasked again, and so forth, many times now in each of the ordinal radiations of mammals. The thrust of this paper has been to ask what is known, what can be surmised and what has yet to be learned about the relationship between photoperiodic cueing and latitude in mammals. The result has been mostly speculative because most of our experimental information about photoperiodic cueing relates to the higher latitudes of the temperate zone.

Life expectancy is a particularly useful parameter around which to organize speculation about photoperiodic cueing and latitude. Short life span dictates opportunism wherever possible. Thus within and between population variation in the use of photoperiodic cueing is expected (and often seen now) even at 
surprisingly high latitudes. For the same reason one often expects to see photoperiodic information overridden by other conditions in short-lived mammals, and one expects to see modification of critical daylength by experience.

Long-lived mammals can afford to rely more exclusively upon photoperiodic regulation over a much larger range of latitudes. Photoperiodic regulation might be employed in a meaningfully way down to about 10 or $15^{\circ}$ of latitude by these animals, and possibly further if supplemented with social synchrony and/or plant predictors. In any case, tropical mammals probably often carry photoperiodic regulation in their gene pool as a selectively neutral trait.

Finally, it must be emphasized that latitude is only one consideration when natural selection manipulates the potential for photoperiodic information to regulate reproduction. Mammalian habitats can vary markedly at any given latitude.

Colloquium on "Neuroendocrine mechanisms and light control of reproduction in domestic mammals " I.N.R.A., Nouzilly, 17-18 September 1987.

Résumé. Intervention des gènes, de la photopériode et de la latitude dans les stratégies de reproduction des Mammifères.

Cet article examine comment et pourquoi la sélection naturelle peut faciliter ou bloquer la régulation photopériodique de la reproduction chez un Mammifère. Les facteurs les plus importants intervenant dans cette décision semblent être les suivants : I'espérance de vie, la longueur du cycle de la femelle, les possibilités de nourriture, la présence ou l'absence de mécanismes de survie telle que l'hibernation et la nature des contraintes saisonnières présentées par l'habitat du Mammifère. Un schéma théorique est présenté pour montrer l'utilité potentielle de ce type de régulation en fonction de l'espérance de vie et de la latitude de l'habitat.

\section{References}

BAKER J. R., RANSON R. M., 1932. Factors affecting the breeding of the field mouse (Microtus agrestis) I. Light. Proc. rov. Soc. B., 110, 312-322.

BRONSON F. H., 1979. The reproductive ecology of the house mouse. Quart. Rev. Biol., 54, 265299.

BRONSON F. H., 1985. Mammalian reproduction : an ecological perspective. Biol. Reprod., 32, $1-26$.

BRONSON F. H., 1988. Seasonal regulation of reproduction in mammals. Vol. 2, 1831-1871. In E. KNOBIL, Physiology of reproduction. Raven Press, New York.

BRONSON F. H., PERRIGO G., 1987. Seasonal regulation of reproduction in muroid rodents. Am. Zool., 27 (in press).

BUDDE W. S., 1983. Effects of photoperiod on puberty attainment of female white-tailed deer. J. Wildl. Mgmt., 47, 595-604.

DARK J., ZUCKER I., WADE G. N., 1983. Photoperiodic regulation of body mass, food intake and reproduction in meadow voles. Am. J. Physiol., 245, R334-R338.

DAVIS D. E., 1953. The characteristics of rat populations. O. Rev. Biol., 28, 373-401.

DELANEY M. J., NEAL B. R., 1969. Breeding seasons in rodents in Uganda. J. Reprod. Fert., Suppl., 6, 229-235. 
DESJARDINS C., LOPEZ M. J., 1980. Sensory and nonsensory modulation of testis function, 381-388. In A. STEINBERGER, E. STEINBERGER, Testicular development, structure and function. Raven Press, New York.

DESJARDINS C., BRONSON F. H., BLANK J., 1986. Genetic selection for reproductive photoresponsiveness in deermice. Nature, 322, 172-173.

DIETERLEN V. F., 1985. Daten zur Fortpflanzung und Populationsstruktur der myomorphen Nager eines afrikanischen Tieflandregenwaldes (Ost-Zaire). Z. Saugetierkunde, 50, 68-88.

DOBROWOLSKA A., GROMADZKA-OSTROWSKA J., 1983. Influence of photoperiod on morphological parameters, androgen concentration, haematological indices and serum protein fractions in common voles (Microtus arvalis, Pall.). Comp. Biochem. Physiol., 74A, 427-433.

EISENBERG J. F., 1981. The mammalian radiations, 610. Univ. Chicago Press, Chicago.

ELLIOTT J. A., 1976. Circadian rhythms and photoperiodic time measurement in mammals. Fed. Proc., 35, 2339-2346.

ELLIOTT J. A., GOLDMAN B. D., 1981. Seasonal reproduction : photoperiodism and biological clocks, 377-423. In N. T. ADLER, Neuroendocrinology of reproduction, Plenum Press, New York.

FOLLETT B. K., FOLLETT D. E., 1981. Biological clocks in seasonal reproductive cycles. 292 pages. Proc. 32nd Symp. Colston Res. Soc. John Wiley \& Sons, New York.

GoSS R. J., 1983. Deer Antlers : regeneration, function and evolution. 316 pages. Acad. Press, New York.

HANSSON L., 1984. Winter reproduction of small mammals in relation to food conditions and population dynamics. Spec. Publ. Carn. Mus. nat. Hist., 10, 225-235.

HASLER J. F., BUHL A. E., BANKS E. M., 1976. The influence of photoperiod on growth and sexual function in male and female collared lemmings. J. Reprod. Fert., 46, 323-329.

HERNDON J. G., 1983. Seasonal breeding in rhesus monkeys : influence of the behavioral environment. Am. J. Primatol., 5, 197-204.

HORTON T. H., 1984. Growth and reproductive development of male Microtus montanus is affected by the prenatal photoperiod. Biol. Reprod., 31, 499-504.

KAIKUSALO A., TAST J., 1984. Winter breeding of microtine rodents at Kilpisjarvi, Finnish Lapland. Spec. Publ. Carn. Mus. nat. Hist., 10, 243-252.

LAM Y. L., 1983. Reproduction in the rice field rat, Rattus argentiventer. Malay Nat. J., 36, 249-282.

LINDEQUE M., SKINNER J. D., 1982. A seasonal breeding in the spotted hyena Crocuta crocuta in southern Africa. Afr. J. Ecol., 20, 271-278.

LYNCH G. R., HEATH H. W., JOHNSTON C. M., 1981. Effect of geographical origin on the photoperiodic control of reproduction in the white-footed mouse, Peromyscus leucopus. Biol. Reprod., 25, 475-480.

MARSHALL A. J., WILKINSON O., 1957. Reproduction of the Orkney vole (Microtus orcadensis) under a six hour daylength and other conditions. Proc. Zool. Soc. Lond., 126, 391-395.

MENAKER M., 1985. Eyes--the second (and third) pineal glands ? 78-79. In Photoperiodism, melatonin and the pineal, Ciba Found. Symp. 117, Pittman Publ. LTD, London.

NELSON R. J., 1984. Proximate factors affecting reproduction in the prairie vole. PhD Thesis, 152 , Univ. California, Berkeley.

NEWSOME A. E., 1965. Reproduction in natural populations of the red kangaroo Megaleia rufa (Desmarest) in Central Australia. Aust. J. Zool., 13, 735-759.

O'CONNELL M. A., 1981. Population ecology of small mammals from Northern Venezuela. PhD Thesis, 283, Texas Tech. Univ., Lubbock.

PETTER-ROUSSEAUX A., 1970. Observations sur l'influence de la photopériode sur l'activité sexuelle chez Microcebus murinus en captivité. Ann. Biol. anim. Biochim. Biophys., 10, 203. 208.

PINTER A. J., NEGUS N. C., 1965. Effect of nutrition and photoperiod on reproductive physiology of Microtus montanus. Am. J. Physiol., 208, 633-638.

RACEY P. A., 1982. Ecology of bat reproduction, 57-104. In T. H. KUNZ, Ecology of bats, Plenum Press, New York.

RISSMAN E., NELSON R. J., BLANK J. L., BRONSON F. H., 1987. Reproductive responses of a tropical mammal to photoperiod. $J$. Reprod. Fert., 81, 563-566. 
RYCHNOVSKY B., 1985. The reproduction of Microtus arvalis under various temperature and lighting conditions. Acta. Sc. nat. Brno, 19, 1-37.

SADLEIR R. M. F. S., 1969. The ecology of reproduction in wild and domestic mammals. Methuen \& Co., 321 p., London.

SILVER R., BITTMAN E. L., 1984. Reproductive mechanisms: interaction of circadian and interval timing, 488-514. In L. ALLEN, J. GIBBON, Timing and Time Perception, New York Acad. Sci. New York.

SMYTH M., 1966. Winter breeding in woodland mice, Apodemus sy/vaticus and voles, Clethrionomys glareolus and Microtus agrestis, near Oxford. J. anim. Ecol., 35, 471-485.

VAN HORN R. N., RESKO J. A., 1977. The reproductive cycle of the ring-tailed lemur (Lemur catta) : sex steroid levels and sexual receptivity under contolled photoperiods. Endocrinology. 101, 1579-1586.

WALLEN E. P., TUREK F., 1981. Photoperiodicity in the male albino lab rat. Nature, 289, $402-404$.

WALTER H., 1971. Ecology of tropical and subtropical vegetation, 235 p., Oliver and Boyd, Edinburgh, Scotland.

WHITTEN P. L., 1983. Females, flowers and fertility. Am. J. Phys. Anth., 60, 269-270.

ZUCKER I., JOHNSTON P. G., FROST D., 1980. Comparative, physiological and biochronometric analyses of rodent seasonal reproductive cycles. Prog. Reprod. Biol., 5, 102-133. 